Provided for non-commercial research and education use. Not for reproduction, distribution or commercial use.

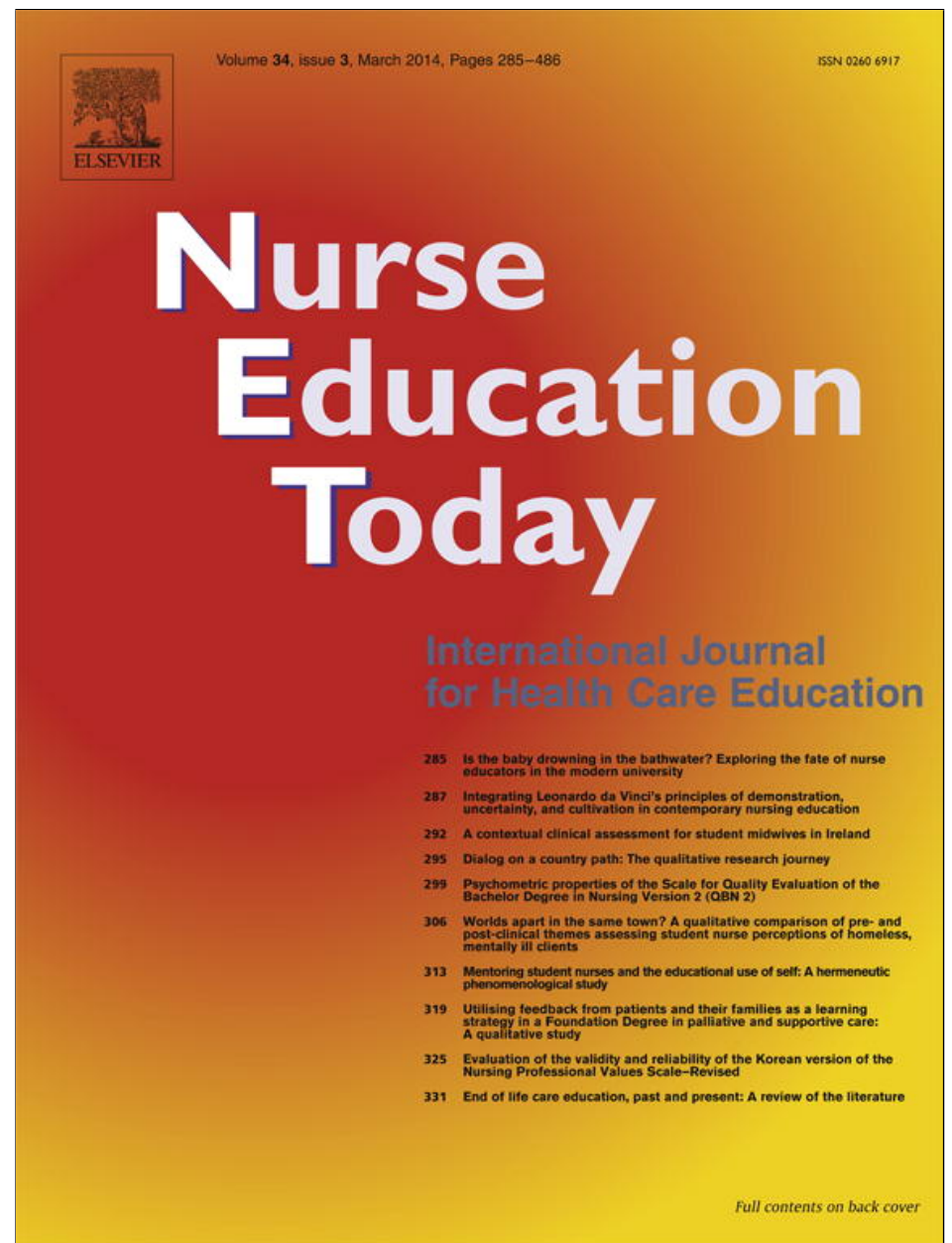

This article appeared in a journal published by Elsevier. The attached copy is furnished to the author for internal non-commercial research and education use, including for instruction at the authors institution and sharing with colleagues.

Other uses, including reproduction and distribution, or selling or licensing copies, or posting to personal, institutional or third party websites are prohibited.

In most cases authors are permitted to post their version of the article (e.g. in Word or Tex form) to their personal website or institutional repository. Authors requiring further information regarding Elsevier's archiving and manuscript policies are encouraged to visit:

http://www.elsevier.com/authorsrights 


\title{
Psychometric properties of the Scale for Quality Evaluation of the Bachelor Degree in Nursing Version 2 (QBN 2)
}

\author{
Loreana Macale $^{\mathrm{a}, 1}$, Gennaro Scialò a,*, Luca Di Sarra ${ }^{\mathrm{a}, 1}$, Maria Grazia De Marinis ${ }^{\mathrm{b}, 2}$, \\ Gennaro Rocco ${ }^{\mathrm{c}, 3}$, Ercole Vellone ${ }^{\mathrm{c}, 4}$, Rosaria Alvaro ${ }^{\mathrm{c}, 5}$ \\ a Nursing Science Degree Faculty of Medicine, Department of Biomedicine and Prevention University of Rome "Tor Vergata", Office of Sora Loc. S. Marciano s.n.c-03039, Sora, FR, Italy \\ ${ }^{\mathrm{b}}$ Campus Biomedico University of Rome, Via Alvaro del Portillo, 20000128 Roma, Italy \\ c Faculty of Medicine, Department of Biomedicine and Prevention University of Rome "Tor Vergata", Via Montpellier 1, 00133 Roma, Italy
}

\section{A R T I C L E I N F O}

\section{Article history:}

Accepted 10 June 2013

\section{Keywords:}

Nursing

Student

Education

Research

Quality indicator

\begin{abstract}
S U M M A R Y
To evaluate all the variables that affect nursing education is important for nursing educators to have valid and reliable instruments that can measure the perceived quality of the Bachelor Degree in Nursing. This study testing the Scale for Quality Evaluation of the Bachelor Degree in Nursing instrument and its psychometric properties with a descriptive design. Participant were first, second and third year students of the Bachelor Degree in Nursing Science from three Italian universities. The Scale for Quality Evaluation of Bachelor Degree in Nursing consists of 65 items that use a 4 point Likert scale ranging from "strongly disagree" to "strongly agree". The instrument comes from a prior version with 41 items that were modified and integrated with 24 items to improve reliability. Six hundred and fifty questionnaires were completed and considered for the present study. The mean age of the students was 24.63 years, $65.5 \%$ were females. Reliability of the scale resulted in a very high Cronbach's alpha (0.96). The construct validity was tested with factor analysis that showed 7 factors. The Scale for Quality Evaluation of the Bachelor Degree in Nursing, although requiring further studies, represents a useful instrument to measure the quality of the Bachelor Nursing Degree.
\end{abstract}

(c) 2013 Elsevier Ltd. All rights reserved.

\section{Introduction}

The Italian National Agency for the Evaluation of Universities and Research Institutes (ANVUR) (2012) defined the quality in university education as the university's ability to establish valuable objectives and achieve them in a way to measure and increase the contiguity between objectives and results. Since the concept of quality in nursing education is wide and susceptible to analysis from a variety of evaluation methodologies, we focused our attention on the concept of perceived quality that favors interactive methodology and is focused on students (Saarikoski et al., 2002; Chan, 2003; Hosoda, 2006; Kari-Sand, 2009).

Evaluating students' satisfaction for the university education is important because it improves the competition among universities, the quality of services students are provided and the prestige of university

\footnotetext{
* Corresponding author. Tel.: + 39 7761938027; fax: + 39 7761938022.

E-mail addresses: loreana.macale@torvergatasora.it (L. Macale),

gennaro.scialo@torvergatasora.it (G. Scialò), lucadisarra1@gmail.com (L. Di Sarra),

m.demarinis@unicampus.it (M.G. De Marinis),g.rocco@mclink.it (G. Rocco),

ercole.vellone@uniroma2.it (E. Vellone), rosaria.alvaro@gmail.com (R. Alvaro).

URLs: http://www.torvergatasora.it (L. Macale), http://www.torvergatasora.it

(G. Scialò).

${ }^{1}$ Tel.: + 39 7761938027; fax: + 397761938022 .

2 Tel.: + 3906225411051 .

${ }^{3}$ Tel.: + 390672596802 ; fax: + 390672596961

${ }^{4}$ Tel.: + 390672596802 , + 393387491811 (mobile); fax: + 390672596961 .

${ }^{5}$ Tel.: + 3906 72596802; fax: +3906 72596961.
}

institutions (Hughes, 2000; Roberts, 1998). It is essential to measure in the academic world how educational aspects directly affect the students and indirectly the training environment with its physical, human, interpersonal and organizational dimensions (Knowles, 2007). It is also essential to evaluate how relational dynamics, cultural and clinical aspects influence the quality of nursing students' education (Cust, 1996).

To evaluate all these variables that affect nursing education it is important for nursing educators to have valid and reliable instruments that can measure the perceived quality of the Bachelor Degree in Nursing Science. Vellone et al. (2007) developed the Scale for Quality Evaluation of the Bachelor Degree in Nursing (QBN). This was a 41-item Likert scale comprising 10 domains. This instrument was tested for its content and discriminant validity and for construct validity as well. Reliability was tested by Cronbach's alpha but, while the first 6 factors showed adequate reliability (Cronbach's alpha $\geq 0.70$ ), 4 factors did not. Therefore, the aim of this study was to modify the QBN in order to have a second version of the instrument with better psychometric properties of validity and reliability. The modified instrument was referred as the Scale for the Quality Evaluation of the Bachelor Degree in Nursing Version 2 (QBN 2).

\section{Background}

For the past 30 years, there has been overwhelming evidence that new graduate nurses are not prepared to enter the workforce 
(Shipman et al., 2012). The American Society for Quality identifies four teaching quality dimensions: responsibility, curricular alignment, assessment and student satisfaction (Brown and Marshall, 2008). An approach based on the process of Continuous Quality Improvement (CQI) (Deming, 1986) showed that all the decisions had to be based on obvious facts demonstrated by objective data analysis, and that all the stakeholders had to know at best their own job description; therefore students, administrators and managers have to be part of the same Continuous Quality Improvement team (Brown and Marshall, 2008; Germini et al., 2010). One of the main learning quality issues concerns students' perception about their own achievements (Kari-Sand, 2009), making it necessary for educators actually evaluate to the students' results and their learning throughout the process (Shipman et al., 2012). The impetus for transformation in nursing education has created the need for educators to evaluate effectively the quality of student achievement and learning through the educational process (Shipman et al., 2012).

The relationship between teacher and student affects the undergraduate performance (Orland-Barack and Wilhelem, 2005; Alvaro et al., 2009) and is considered a positive aspect between teachers and students (Wilkes, 2006). Student evaluation should create a supporting learning environment and a positive atmosphere for the student (Jokelainen et al., 2011; Saarikoski et al., 2002; Pearcey and Elliott, 2004) that encourages good relationship with colleagues, discussions and encourages students' curiosity (Kell and Jones, 2007; Senge, 2006; Henderson et al., 2012; Chan, 2001). In addition, during the learning process students want to be treated as individuals and colleagues so students' learning independence, responsibility and self-management are increasingly important (Andrews and Chilton, 2000). Some authors (Pellatt, 2006; Bray and Nettleton, 2007; Webb and Shakespeare, 2008) have suggested organizing teaching in a formal, impartial, constructive and objective manner without the influence of other factors like friendship. Furthermore, the highlights for clinical learning are acceptance and orientation, intermediate evaluation (formative) and final evaluation (certification) (Kim, 2003; Scalorbi and Burrai, 2008). In this perspective, some authors stated that classroom learning didactic does not have any advantages compared to on-line learning didactic (Billings, 2000; Schoech and Helton, 2003; Bata-Jones and Avery, 2004; Wells and Dellinger, 2011), but there are still controversies about the issue (Rovai, 2002; Frith and Kee, 2003). In this context it is also important the "peer" student relationship (Bonnel et al., 2007; Bulfone et al., 2008): the discussion among colleagues is considered a teaching method (Stevens and Levi, 2005), even if the students are reluctant to express negative opinions on colleagues or correct them based on didactic value (Chaves et al., 2006).

In the Italian Bachelor Degree in Nursing there are different teacher categories with different backgrounds: nursing teachers have different experiences so a systematic evaluation is important (Herbert et al., 2002). The number of sessional teachers is increasing followed by a decreasing number of tenured teachers, especially in practical disciplines like nursing (Kovner et al., 2006; Thedwall, 2008). However, from the literature it emerged that sessional teachers are recruited with less strict criteria than tenured teachers (Herbert et al., 2002; Andrew et al., 2010), consequently, sessional teachers are often lacking of pedagogical notions and didactic principles (Herbert et al., 2002; Anibas et al., 2009; Andrew et al., 2010). This is perceived by the students as weak commitment, lack of preparation, inappropriate qualification and inadequate performance management (Percy et al., 2008; Anibas et al., 2009; Halcomb et al., 2010). Sessional teachers' grades are higher than those given by tenured teachers (Kezim et al., 2005; Cavanaugh, 2006; Salamonson et al., 2010). Furthermore, Cavanaugh (2006) indicates that this is a strategy to reduce students' potential complaints about teaching and to improve their teachers' evaluations (Landrum, 2009; Salamonson et al., 2010). However, it was shown that for sessional teachers positive evaluations, high passing rate and a low number of students' negative comments can have an important role on contract renewal (Halcomb et al., 2010). According to students' evaluations, sessional teachers are often considered inexperienced (Salamonson et al., 2010); and since those teachers are seen as more enthusiastic in their job (Green and Baird, 2009) compared to tenured teachers, in their classes students often learn more. On the contrary, students attending the last year of course tend to evaluate tenured teachers better than sessional ones. Some authors state that this is due to students' maturity (Salamonson et al., 2010), and the need of a wider and professional nursing knowledge that is likely to be provided by tenured teachers (Egan and Jaye, 2009).

Another important concept to consider when measuring degree courses' quality is the dropout prevention, the students abandoning the courses are usually those who had low grades in pre-entrance tests (Houltram, 1996; Kevern et al., 1999; Pryjmachuk et al., 2009), with parents who did not graduate, with a lower socioeconomic status; other important factors are student's age (Houltram, 1996; Kevern et al., 1999; Mulholland et al., 2008; Pryjmachuk et al., 2009), gender (Mulholland et al., 2008; Pryjmachuk et al., 2009) and course's topic (Higher Education Funding Council England, 2000; McMillan, 2005; Jeffreys, 2007). However, just one factor can be sufficient to cause drop out. Almost $50 \%$ of the students say that they have two causes of courses drop out (Glossop, 2002). Furthermore; factors promoting course pursuance are being taken care of by a competent nurse (Sadler, 2003; Lai et al., 2008); conceptualizing "being" a nurse, and not "acting like" a nurse (Kotecha, 2002); having good tutors or close relatives performing the same job (Bowden, 2008); having tenured teachers instead of sessional ones (Colalillo, 2007; Sutherland et al., 2007); having the chance to share the same experiences with fellow students (Rudel, 2006; Bowden, 2008; Green and Baird, 2009); developing a "sense of belonging" to the campus (Levett-Jones et al., 2009). Moreover, a positive profession's image strengthens the vision of a career as a nurse, while a negative image interferes with career planning (Pearcey and Elliott, 2004). A clear comprehension and appreciation of students' satisfaction are fundamental to improve educational processes, education's quality and to evaluate institutional efficiency (Kantek and Kazanc1, 2012).

\section{Aim}

The aim of this study was to test the psychometric properties of the QBN 2. Specifically, we tested the validity of the QBN 2 by exploratory factor analysis and then we tested its internal consistency and test-retest reliability.

\section{Methods}

\section{Design}

A descriptive design was used to carry out the study.

\section{Instruments}

\section{The Sociodemographic Questionnaire}

This instrument was developed by an expert panel (formed by a Nursing Associate Professor, three nurses with a PhD in Nursing Science, one nursing researcher, three Bachelor Degree in Nursing programs' directors), in order to collect information such as high school diploma and grade obtained, any formative experiences with other faculty and/or university degree courses, average grade for taken exams, lesson attendance percentage, how far was the campus from where they lived and the means of transport.

The Scale for Quality Evaluation of Bachelor Degree in Nursing Version 2 (QBN 2)

It consists of 65 items that use a 4 point Likert scale ranging from "strongly disagree" to "strongly agree". The instrument comes from a prior version with 41 items (Vellone et al., 2007) that were modified 
and integrated with 24 items to improve reliability. The items' modification and integration were done because, in the prior version of the scale some items investigated with one question more than one content and consequently they loaded on more than one factor. Also, for this reason, the unclear factors were not well identified. For example, one factor of the QBN Version 1 was named "Characteristics of teachers and clinical tutors" and another was named "Tutor competences": indeed competences of tutors are also characteristics. Examples of items are: At the beginning of the course I received sufficient information about the program and its educational objectives; There was an adequate correspondence between acquired theoretical knowledge and the clinical training objectives; The methods of the examinations have been clearly defined.

\section{Sample and Procedures}

We selected a convenience sample of students from three different universities in Lazio and Calabria regions. Participants were first, second and third year students of the Bachelor Degree in Nursing Science. No exclusion criteria were established for the study so the instruments were administered to all students. The questionnaire was administered in the classroom outside of lessons after explaining the purpose of the study and the students were reassured that the questionnaires were anonymous. A total of 663 participants were asked to take part in the study but thirteen students form Lazio and three from Calabria regions refused to participate in the study without giving a particular reason. The final sample was composed by 650 participants. Twenty five students of the University of Rome "Tor Vergata" Sora Campus volunteered to complete the SQEBDN 2 after 2 weeks from the first administration for test re-test.

\section{Ethical Considerations}

The study was approved by the Dean of each university and the permission of each school department's director was obtained. Participation was voluntary and the students were told that they could leave at any time, being involved would have no effect on course's attendance, and that confidentiality would be maintained at all times. The researcher was not aware of the student's identity.

\section{Data Analysis}

Descriptive statistics were computed on the student's sociodemographic data. Specifically, mean SD, and frequencies were computed. Descriptive statistics were also used to describe item responses. Construct validity of the QBN 2 was established by exploratory factor analysis (EFA). EFA was performed with the method of principal axis factoring with promax rotation. To choose the best factor solution the following criteria were considered: the theoretical conceptualization of the quality in nursing education, the number of items not loading on any factor, the presence of factors with few items, the number of items loading on more than one factor, and the interpretability of the factors (Barbaranelli, 2007; Vellone et al., 2013). For item retention was applied the criteria of loading $\geq .30$ (Barbaranelli, 2007). Applying these criteria to 7 factor solution was preferred. Internal consistency reliability of the factors extracted by EFA was tested by Cronbach's alpha. In addition also test-retest reliability was performed by intraclass correlation coefficient (ICC). Both for Cronbach's alpha and ICC a coefficient $\geq .70$ was considered adequate reliability. The level of significance was set at $\mathrm{p}<0.05$. The software used for data analysis was SPSS 19.0.

\section{Results}

\section{Socio Demographic Characteristics}

A total of 663 participants were asked to take part in the study but 13 refused to participate without giving a particular reason. The final sample was composed by 650 participants. Table 1 reports the sociodemographic variables regarding the participants. Students had a mean age of 25 years and were mostly females. All year courses were equally represented in the sample but the third year was less. The average exams' grade achieved by the students was twenty-four on a maximum score of thirty. These data, in reference to age and gender, are very similar to the Nursing Bachelor Degrees' Students' National Statistics, where the age range mostly represented was between 21 and 30 years and females represent the $69 \%$ of all students (Italian Ministry of University, 2013).

\section{Validity Testing}

EFA resulted with a 7-factor solution which is reported in Table 2. The first factor was named Quality of teacher, describing teacher features such as capability to stimulate students' interest, make correlations with other disciplines, use of different teaching methods and encouragement of students. The second factor was named Quality of services and support organization describing classroom and clinical learning, library and other services offered to the students, administrative staff qualities. The third factor was named Quality of clinical training and grouped items regarding tutorship and clinical tutors' competences. Didactic organization and quality of evaluation was the name given to the fourth factor since in included didactic aspects and teaching aids, the didactic organization of bachelor degree courses (pre-requisites and disciplines coordination and management, examination modality and the use of teaching aids). The fifth factor was named Interests and objectives because of its semantic contents pertaining to the topics of the disciplines and their relevance. The Quality of administrative services was the sixth factor with items investigating the registrar's office staff and services. The seventh factor was named Identity and belongings and comprised items investigating the sense of professional identity and belonging. All seven factors explained the $51.8 \%$ of the total variance.

\section{Reliability Testing}

Internal consistency reliability was satisfactory for each QBN 2 factor (Table 3), ranging from 0.94 for the Quality of teacher to 0.76 for the Interests and objectives factor.

Test-retest reliability was satisfactory for the factors Quality of clinical training and Didactic Organization and Quality of Evaluation but unsatisfactory for the factors Quality of teachers, Quality of services and support organization, Interests and objectives, Quality of administrative services, Identity and belongings (Table 4).

Table 1

Sociodemographic data about the sample $(\mathrm{N}=650)$.

\begin{tabular}{lrl}
\hline & Mean & SD \\
\hline Age & 24.63 & 5.4 \\
& $\mathrm{~N}$ & $(\%)$ \\
\hline Gender & & \\
$\quad$ Female & 426 & $(65.5)$ \\
$\quad$ Male & 224 & $(34.5)$ \\
School of nursing & & \\
$\quad$ University of Rome "Cattolica del Sacro Cuore" Rome Campus & 140 & $(21.5)$ \\
$\quad$ University of Rome "Tor Vergata" Fatebenefratelli Campus & 53 & $(8.0)$ \\
$\quad$ University of Rome "Tor Vergata" Marinella Di Bruzzano & 116 & $(17.8)$ \\
$\quad$ Campus & & \\
$\quad$ University of Rome "La Sapienza" "IFO" Regina Elena Campus & 89 & $(13.7)$ \\
$\quad$ University of Rome "Tor Vergata" Sora Campus & 252 & $(38.8)$ \\
Course year & & \\
I year & 223 & $(34.3)$ \\
II year & 238 & $(36.6)$ \\
III year & 165 & $(25.4)$ \\
$\quad$ Out of course & 19 & $(2.9)$ \\
Average exams'grade (SD) & 23.94 & $(6.5)$ \\
\hline
\end{tabular}


Table 2

Exploratory Factor Analysis of the QBN 2.

Pattern matrix

\begin{tabular}{|c|c|c|c|c|c|c|c|}
\hline & \multicolumn{7}{|l|}{ Factor } \\
\hline & 1 & 2 & 3 & 4 & 5 & 6 & 7 \\
\hline Item 49 . Teachers have been understanding towards students' problems & .787 & -.023 & -.028 & .124 & -.184 & .015 & .029 \\
\hline Item 52. Teachers gave indications on study method for their discipline & .769 & .057 & -.013 & .060 & -.081 & -.040 & -.107 \\
\hline Item 42. Teachers stimulated students' active participation & .748 & .023 & .051 & -.140 & .092 & -.086 & -.001 \\
\hline Item 53 . Teachers were emotionally stable & .708 & .063 & -.031 & -.228 & .094 & .003 & .063 \\
\hline Item 39. Teachers lectured in a clear and satisfactory way & .698 & -.066 & -.005 & .134 & -.107 & .073 & -.026 \\
\hline Item 48 . Teachers based their lectures on students' learning abilities & .697 & -.006 & -.038 & .051 & .093 & -.041 & -.021 \\
\hline Item 47. Teachers have been able to combine theoretic and clinical aspects while lecturing & .679 & .239 & .056 & -.140 & -.067 & -.073 & .008 \\
\hline $\begin{array}{l}\text { Item } 50 \text {. Teachers used several teaching methods at the same time (multimedia tools, demonstrations, group } \\
\text { discussion, written tests, integration with other teachers, etc.) }\end{array}$ & .676 & .024 & -.052 & .135 & -.064 & -.011 & .009 \\
\hline Item 43. Teachers used teaching aids adequately (blackboard, transparencies, slides, computer, video, etc.). & .665 & -.010 & -.021 & .046 & -.017 & .030 & -.037 \\
\hline Item 41. Teachers stimulated interest for their discipline & .606 & -.198 & -.012 & .208 & .234 & -.051 & -.077 \\
\hline Item 51. Teachers were able to manage the class & .578 & .212 & .109 & -.105 & -.126 & .037 & -.029 \\
\hline Item 45 . Teaching aids used and suggested by teachers were adequate for the study of their discipline & .572 & -.131 & .033 & .085 & .194 & .018 & -.061 \\
\hline Item 65 . Teachers were competent teaching their discipline & .559 & -.114 & .020 & .128 & .094 & .038 & .031 \\
\hline Item 40 . Teachers thoroughly answered to students' clarification requests & .547 & -.111 & -.016 & .033 & .216 & .080 & -.015 \\
\hline Item 46 . While lecturing teachers made connections with other disciplines & .540 & -.035 & -.022 & .092 & .030 & .053 & .057 \\
\hline Item 54. The optional didactic activities were helpful for learning purposes & .533 & .233 & .019 & -.183 & .249 & -.030 & -.025 \\
\hline Item 44 . Teachers provided the students lecture notes or a bibliography to study on & .474 & -.045 & .086 & -.011 & .135 & .119 & .162 \\
\hline Item 25 . Integrated courses have been actually held in an "integrated" way & -.004 & .835 & -.043 & .127 & -.088 & -.104 & .081 \\
\hline $\begin{array}{l}\text { Item } 16 . \text { The library was well organized (business hours, accommodation, staff availability, efficient } \\
\text { consultation, etc.). }\end{array}$ & .013 & .789 & -.033 & -.094 & .065 & -.015 & .053 \\
\hline Item 14 . The simulation laboratory was adequate (student could see, could hear, could take notes, could find a seat) & .034 & .781 & -.048 & .081 & -.136 & -.057 & .055 \\
\hline Item 17. The number of computers available to the students was adequate & .001 & .701 & -.099 & .111 & -.046 & -.022 & .106 \\
\hline Item 8. Didactic activities were well executed in the simulation laboratory & -.084 & .674 & .009 & .160 & -.024 & -.023 & .058 \\
\hline Item 21 . The restaurant service was well organized & -.094 & .568 & .015 & .014 & .115 & .009 & -.077 \\
\hline Item 13. Teaching aids were adequate and sufficient & .020 & .548 & -.032 & -.265 & .374 & .109 & -.106 \\
\hline $\begin{array}{l}\text { Item } 12 . \text { The classrooms where the lectures took place were adequate (we could see, hear, take notes, find a place } \\
\text { to seat) }\end{array}$ & .076 & .441 & .029 & -.130 & .373 & .089 & -.177 \\
\hline Item 15. The dressing rooms were adequate for students' needs & .014 & .391 & .152 & .076 & -.033 & .003 & -.036 \\
\hline Item 9. The time dedicated to hands-on practice has been sufficient & .087 & .337 & .043 & .025 & .138 & .035 & -.031 \\
\hline Item 22. Adequate space for recreational activities was available (to have a coffee, to have a conversation etc.) & -.014 & .295 & .118 & .161 & .113 & -.045 & -.046 \\
\hline Item 7 . The didactic activities in small groups were well carried out & -.066 & -.020 & .792 & -.281 & .068 & .034 & .067 \\
\hline Item 60 . The nurses involved in clinical teaching had field experience & .011 & -.106 & .762 & .001 & -.076 & .000 & .026 \\
\hline Item 57. The clinical premises' nurses have been competent & .055 & -.036 & .679 & -.005 & -.006 & -.057 & .194 \\
\hline Item 61. I'm overall satisfied about education's quality & .108 & .074 & .634 & .083 & -.260 & -.068 & -.042 \\
\hline Item 55. The clinical premises' nurses involved me in their work & -.025 & -.111 & .593 & -.072 & .246 & -.028 & -.028 \\
\hline Item 58. The nurses on duty in clinical training premises were aware of student's learning objectives & .039 & .037 & .572 & -.022 & -.133 & .026 & -.005 \\
\hline Item 10. Clinical training was well executed & -.175 & .027 & .567 & .015 & .270 & .010 & -.017 \\
\hline Item 27. I have been well received to clinical premises & .111 & .152 & .395 & .136 & -.172 & .052 & .094 \\
\hline Item 59. Tutors ensured clinical training supervision & .130 & .143 & .371 & .111 & .048 & .067 & .163 \\
\hline Item 26. Preliminary education to clinical activities was satisfactory & .143 & .110 & .310 & .152 & .192 & -.066 & -.125 \\
\hline Item 56. The nursing documentation available at clinical premises was appropriate & .003 & .193 & .017 & .563 & -.083 & -.032 & .052 \\
\hline Item 23. I'm overall satisfied about how this academic year went & .086 & .104 & -.186 & .542 & -.075 & -.003 & .074 \\
\hline Item 34. The examination's methods have been clearly defined & .085 & .265 & -.018 & .404 & .072 & .021 & -.027 \\
\hline Item 6. Theoretical courses with their training and exams allowed an optimal path in studies & .086 & .017 & .028 & .402 & .081 & .008 & -.010 \\
\hline Item 35. Exams adequately evaluated student's knowledge & .225 & .006 & .123 & .398 & -.010 & .040 & -.069 \\
\hline Item 33. Teaching aids (indicated or provided) were appropriate for the study of each discipline & .080 & .304 & -.130 & .389 & .034 & .015 & -.011 \\
\hline Item 3. The time between classroom activities and other activities was well distributed & -.015 & .340 & .029 & .377 & -.100 & .099 & -.011 \\
\hline Item 2. Lectures' schedule was well organized & .240 & .050 & -.108 & .365 & .032 & -.107 & -.007 \\
\hline Item 31. Teaching plan complied with propaedeutic criteria between disciplines & .151 & -.011 & .021 & .349 & .135 & .017 & .058 \\
\hline Item 37. Teachers were on time and regularly present for lectures & .219 & -.065 & .080 & .333 & .062 & -.005 & -.123 \\
\hline Item 38. Teachers provided a teaching plan for their discipline to the students & .211 & .004 & -.004 & .329 & .136 & .009 & -.079 \\
\hline Item 1 . The total study load has been acceptable & .250 & .061 & .029 & .309 & .106 & .043 & .003 \\
\hline Item 36. My exams' results reflected my actual knowledge & -.074 & .188 & -.073 & .296 & .231 & .138 & .030 \\
\hline $\begin{array}{l}\text { Item } 11 \text {. There was an adequate correspondence between acquired theoretical knowledge and clinical training's } \\
\text { objectives }\end{array}$ & -.058 & .145 & .273 & .277 & .212 & -.079 & -.069 \\
\hline $\begin{array}{l}\text { Item } 4 \text {. At the beginning of the course I received sufficient information about the program and its educational } \\
\text { objectives }\end{array}$ & .204 & .130 & -.076 & .275 & .138 & .008 & .067 \\
\hline Item 32. The hours assigned to the disciplines were sufficient for teachers to complete their program & .106 & -.134 & -.084 & .051 & .677 & -.120 & .294 \\
\hline Item 30. The several disciplines' contents did not overlap & .178 & -.045 & -.069 & -.020 & .626 & -.052 & .245 \\
\hline Item 24. The topics treated in the different disciplines were interesting & .143 & -.063 & -.045 & .044 & .560 & -.093 & .303 \\
\hline Item 28. The disciplines that I studied were interesting & .108 & .150 & -.056 & .194 & .387 & -.027 & -.020 \\
\hline Item 29. The disciplines that I studied were pertaining to the course's educational objectives & .080 & .250 & .011 & .226 & .264 & .124 & .033 \\
\hline Item 5 . Theoretic didactic was well executed & .240 & .014 & -.031 & .233 & .255 & .040 & -.024 \\
\hline Item 20. The information given to the students by the registrar's office have been clear and correct & -.014 & -.097 & -.007 & .040 & -.087 & .879 & .024 \\
\hline Item 19. Registrar's office staff was kind and helpful & .003 & .006 & -.010 & -.027 & -.084 & .862 & .051 \\
\hline Item 18. Registrar's office services were well organized & .051 & .023 & -.016 & -.030 & -.044 & .806 & .010 \\
\hline Item 64. I would suggest to enroll to the Bachelor in Nursing Science to other people & -.027 & .088 & .047 & -.054 & .217 & .062 & .712 \\
\hline Item 63. If I could go back in time I would still enroll to the Bachelor in Nursing Science & -.030 & .122 & .043 & .020 & .193 & .026 & .703 \\
\hline Item 62. Once I obtain my nursing degree I plan to achieve other academic titles in this field & -.090 & -.085 & .159 & .068 & .187 & .029 & .401 \\
\hline
\end{tabular}

Extraction method: principal axis factoring.

Rotation method: promax with Kaiser normalization. Boldface identifies the primary factor on which the item loads. 
Table 3

Internal consistency of the QBN 2.

\begin{tabular}{llc}
\hline Factors & $\begin{array}{l}\text { Cronbach's } \\
\text { alpha }\end{array}$ & No. of items \\
\hline 1) Quality of teachers & 0.94 & 18 \\
2) Quality of services and support organization & 0.88 & 11 \\
3) Quality of clinical training & 0.86 & 10 \\
4) Didactic organization and quality of evaluation & 0.89 & 16 \\
5) Interests and objectives & 0.77 & 4 \\
6) Quality of administrative services & 0.86 & 3 \\
7) Identity and belongings & 0.76 & 3 \\
Scale total & 0.96 & 65
\end{tabular}

\section{Discussion}

Some items loading to more than one dimension created some slight problems to the tool's structure. The dimension's internal consistency emerged by principal axis factoring through reliability analysis for each dimension, reliability coefficients (Cronbach $\alpha$ ) were as follows (Table 3): 0.9 for first dimension "teachers' quality", 0.8 for second dimension "services and support organization's quality", 0.8 for third dimension "clinical training's quality", 0.8 for fourth dimension "didactic organization and evaluation's quality", 0.7 for the fifth dimension "interests and objectives", 0.8 for the sixth "administrative services' quality", and 0.7 for the seventh "identity and belongings". The results showed high scores in all domains since all the Cronbach $\alpha$ values were ranging from 0.70 to 0.94 , in addition, the tool's reliability coefficient was 0.96 . Based on an analysis of 650 student evaluation and also with expert panel advice, the SQEBDN 2 demonstrated strong internal consistency both within domains and as a tool overall. From construct validation emerged through factor analysis, a Bachelor of Nursing Science Degree Course quality model could be outlined, however, more studies are needed to evaluate the kind of relationship between these dimensions. Some item loadings were below the cut-off point of .30 but they were retained because their content was considered important from the research team for evaluation.

From construct validation emerged education's quality domains not similar to the ones described in international literature, this emphasizes how much cultural differences can influence the results and how it is necessary to develop specific and context related tools. Furthermore, other studies are necessary to improve the developed tool, the Bachelor of Nursing Science Degree's quality could be differently conceptualized so the items could be different from the assessed ones. Education's quality is a wide and multifaceted concept: the work could be improved by the participation of other disciplines' experts in education's quality to the research group. The SQEBDN 2 is a prismatic tool which can be considered valid and reliable to investigate different basic nursing education's quality domains. The unsatisfactory test-retest reliability of quality of teachers, quality of services and support organization, interests and objectives, quality of administrative services, and identity and belongings, might be explained by a low sample size (25 subjects) used for re-test (Table 4).

Table 4

Test retest reliability of the SQEBDN 2.

\begin{tabular}{llrl}
\hline & ICC & \multicolumn{1}{l}{ CI 95\% } & p \\
\hline 1) Quality of teachers & 0.65 & $0.19-0.85$ & 0.007 \\
2) Quality of services and support organization & 0.63 & $0.17-0.85$ & 0.005 \\
3) Quality of clinical training & 0.79 & $0.51-0.91$ & 0.000 \\
4) Didactic organization and quality of evaluation & 0.76 & $0.45-0.90$ & 0.001 \\
5) Interests and objectives & 0.57 & $0.01-0.81$ & 0.002 \\
6) Quality of administrative services & 0.34 & $-0.52-0.74$ & 0.16 \\
7) Identity and belongings & 0.59 & $0.25-0.80$ & 0.001 \\
\hline
\end{tabular}

\section{Limitations}

The first limitation of this study was the enrollment of a convenience sample even though it was comparable to the national situation. The limitation to the present study includes the fact that the tool was administered only to students who are regularly attending classes, missing the opinions of the out of course students (not regularly attending classes) who are representing a wider population. Furthermore the out of course students' choice can itself be a consequence of dissatisfaction towards teachers, didactic organization of Bachelor of Nursing Science Degree Courses or towards teaching and evaluating methods. In addition, other limitations are due to real students' opinion in the questionnaire filling because their point of view on a course's quality could be influenced by several factors. These include their real capability to appreciate and judge didactic activities "on the spot", or how much their effective interest for the discipline could influence their expressed opinions. Finally, in future studies the qualitative data of students', teachers' and clinical instructors' perceptions would be a useful addition.

\section{Conclusions}

The SQEBDN 2 is a tool that can be used to evaluate students' perceived quality of the Bachelor Degree in Nursing Science and consequently can be used to improve their educational level. This tool could be useful to determine changes in the nursing complex environment, where the research of students, nurse teachers' satisfaction (Gui et al., part II, 2009) and staff's organizational well-being can and has to find new ways of achievement and has to be constantly monitored. More in details, this instrument can be used to evaluate and monitor several dimensions of student satisfaction and consequently may allow specific interventions. For example, by administering the SQEBDN 2 nursing schools can evaluate and monitor teachers' quality or administrative services' quality and eventually make changes. Users of the SQEBDN 2 can compute both not only a total score to evaluate the global quality of the Bachelor Degree but also a score for each individual factor. Because the factors have different numbers of items, to make each factor score and the total scale score comparable we recommend the use of a standardized score from 0 to 100 with higher score meaning better quality. In Appendix A the name and the e-mail of the investigator are reported. The user can contact him for permission to use the SQEBDN 2 and to have the SPPS syntax for the scoring procedures. More studies with larger samples of students in different settings are needed, therefore, a qualitative phase would be useful to investigate and comprehend the expectations and the experiences that, in this first research step, remained obscure.

\section{Author Contributions}

Conception and design of the study: LM, EV.

Acquisition of data: LDS.

Analysis and interpretation of data: GS, MGDM, GR, EV.

Drafting the article: LM, GS.

Critical revise: EV.

Final approval of the version to be submitted: RA.

\section{Fundings and Conflict of Interest}

This study was not supported by any external funding and there are no conflicts of interest.

\section{Acknowledgments}

The authors would like to thank Antonella Palombo, LPN, for providing language help and writing assistance. 


\section{Appendix A}

Permission to use the QBN should be sent to Dr. Ercole Vellone, e-mail: ercole.vellone@uniroma2.it.

\section{References}

Alvaro, R., Vellone, E Fierro, A., Faia, A Petrone, F, Miliani, R, Venturini, G., 2009. Strumenti e metodi per migliorare il tirocinio clinico degli studenti del Corso di Laurea in Infermieristica: esperienza dell'Università di Roma Tor Vergata. Professioni Infermieristiche 62, 32-40.

Andrew, S., Halcomb, E.J., Jackson, D., Peters, K., Salamonson, Y., 2010. Sessiona teachers in a BN program: bridging the divide or widening the gap? Nurse Education Today 30 (5), 453-457.

Andrews, M., Chilton, F., 2000. Student and mentor perceptions of mentoring effectiveness. Nurse Education Today 20 (7), 555-562.

Anibas, M., Brenner, G.H., Zorn, C.R., 2009. Experiences described by novice teaching academic staff in baccalaureate nursing education: a focus on mentoring. Journal of Professional Nursing 25 (4), 211-217.

Barbaranelli, C., 2007. Data Analysis With SPSS. Analisi dei dati con SPSS. Le analisi di base. Edizioni Led, Milano (ISBN 978-88-7916-346-X).

Bata-Jones, B., Avery, M., 2004. Teaching pharmacology to graduate nursing students: evaluation and comparison of web-based and face-to-face methods. Journal of Nursing Education 43 (4), 185-189.

Billings, D., 2000. A framework for assessing outcomes and practices in web-based courses in nursing. Journal of Nursing Education 39 (2), 60-67.

Bonnel, W., Ludwig, C., Smith, J., 2007. Providing feedback in online courses: what do students want? How do we do that? Annual Review of Nursing Education 6 , 205-221.

Bowden, J., 2008. Why do nursing students who consider leaving stay on their courses? Nurse Researcher 15 (3), 45-58.

Bray, L., Nettleton, B., 2007. Assessor or mentor? Role confusion in professional education. Nurse Education Today 27 (8), 848-855

Brown, J.F., Marshall, B.L., 2008. Continuous quality improvement: an effective strategy for improvement of program outcomes in a higher education setting. Nursing Education Perspectives 29 (4), 205-211.

Bulfone, G., Galletti, C., Vellone, E., Zanini, A., Quattrin, R., 2008. L'abilità di problem solving dello studente infermiere: l'esperienza del Corso di Laurea in Infermieristica dell'Università di Udine. Professioni Infermieristiche 61, 139-148.

Cavanaugh, J.K., 2006. What did you get? A faculty grade comparison. Quality Assurance in Education 14 (2), 179-186.

Chan, D.S., 2001. Development of an innovative tool to assess hospital learning environments. Nurse Education Today 21 (8), 624-631.

Chan, D.S., 2003. Validation of the clinical learning environment inventory. Western Journal of Nursing Research 25 (5), 519-532.

Chaves, J.F., Baker, C., Chaves, J.A., Fisher, M., 2006. Self, peer, and tutor assessments of MSN competencies using the PBL evaluator. Journal of Nursing Education 45 (1), $25-31$.

Colalillo, G., 2007. Mentoring as a retention strategy in a diverse, multicultural, urban associate degree nursing program. Teaching and Learning in Nursing 2, 28-33.

Cust, J.A., 1996. Relational view of learning: implications for nurse education. Nurse Education Today 16 (6), 256-266.

Deming, W.E., 1986. Out of the Crisis. Massachusetts Institute of Technology, Center for Advanced Engineering Study, Cambridge, MA.

Egan, T., Jaye, C., 2009. Communities of clinical practice: the social organization of clinical learning. Health: An Interdisciplinary Journal for the Social Study of Health, Illness \& Medicine 13 (1), 107-125.

Frith, K., Kee, C., 2003. The effect of communication on nursing student outcomes in web-based course. Journal of Nursing Education 42 (8), 350-358.

Germini, F., Vellone, E., Venturini, G., Alvaro, A., 2010. Gli outcomes del nursing: strumenti per rendere visibile l'efficacia dell'assistenza infermieristica. Profession Infermieristiche 63, 205-210.

Glossop, C., 2002. Student nurse attrition: use of an exit-interview procedure to determine students' leaving reasons. Nurse Education Today 22 (5), 375-386.

Green, S., Baird, K., 2009. An exploratory, comparative study investigating attrition and retention of student midwives. Midwifery 25, 79-87.

Gui, L., Barriball, K.L., While, A.E., 2009b. Job satisfaction of nurse teachers: a literature review. Part II: effects and related factor. Nurse Education Today 29 (5), 477-487.

Halcomb, E.J., Andrew, S., Peters, K., Salamonson, Y., Jackson, D., 2010. Casualisation of the teaching workforce: implications for nursing education. Nurse Education Today 30 (6), 528-532.

Henderson, A., Cooke, M., Creedy, D.K., Walker, R., 2012. Nursing students' perceptions of learning in practice environments: a review. Nurse Education Today 32 (3), 299-302.

Herbert, D., Hannam, R., Chalmers, D., 2002. Enhancing the training, support and management of sessional teaching staff. Available: https://www.aare.edu.au/02pap/ her02448.htm.

Higher Education Funding Council England, 2000. Performance Indicators in Higher Education. Higher Education Funding Council England, London.

Hosoda, Y., 2006. Development and testing of a Clinical Learning Environment Diagnostic Inventory for baccalaureate nursing students. Journal of Advanced Nursing 56 (5), 480-490

Houltram, B., 1996. Entry age, entry mode and academic performance on a Project 2000 common foundation programme. Journal of Advanced Nursing 23 (6), 1089-1097.
Hughes, K., 2000. Quality and marketing issues in nursing education. British Journal of Nursing 9, 763-768.

Italian Ministry of University, 2013. Anagrafe nazionale studenti. http://anagrafe.miur. it/index.php (Last access May 5, 2013).

Jeffreys, M.R., 2007. Tracking students through program entry, progression, graduation and licensure: assessing undergraduate nursing student retention and success. Nurse Education Today 27 (5), 406-419.

Jokelainen, M., Turunen, H., Tossavainen, K., Jamookeeah, D., Coco, K., 2011. A systematic review of mentoring nursing students in clinical placements. Journal of Clinical Nursing 20 (19-20), 2854-2867.

Kantek, F., Kazanc1, G., 2012. An analysis of the satisfaction levels of nursing and midwifery students in a health college in Turkey. Contemporary Nurse 42 (1), 36-44 (2012 Aug).

Kari-Sand, J., 2009. Assessing nursing student perceptions of the clinical learning environment: refinement and testing of the SECEE inventory. Journal of Nursing Measurement 17 (3), 232-246.

Kell, C., Jones, L., 2007. Mapping placement educators' conceptions of teaching. Physiotherapy 93, 273-282.

Kevern, J., Ricketts, C., Webb, C., 1999. Preregistration diploma students: a quantitative study of entry characteristics and course outcomes. Journal of Advanced Nursing 30 (4), 785-795.

Kezim, B., Pariseau, S.E., Quinn, F., 2005. Is grade inflation related to faculty status? The Journal of Education for Business 80 (6), 358-364

Kim, K.H., 2003. Baccalaureate nursing students' experiences of anxiety producing situations in clinical setting. Contemporary Nurse 14 (2), 145-155.

Knowles, M., 2007. Quando l'adulto impara pedagogia e andragogia. Franco Angeli, Milano.

Kotecha, M., 2002. Exploring nurse learner wastage/persistence using a discursive approach: towards a theoretical understanding of the subject. Journal of Advanced Nursing 40 (2), 210-217.

Kovner, C., Fairchild, S., Jacobson, L. 2006. Nurse Educators 2006: A Report of the Faculty Census Survey of RN Programs and Graduate Programs. National League for Nursing, New York.

Lai, H., Lin, Y., Chang, H., Chen, C., Peng, T., Chang, F., 2008. Is nursing profession my firs choice? A follow up survey in preregistration student nurses. Nurse Education Today 28 (6), 768-776.

Landrum, R., 2009. Are there instructional differences between full-time and part-time faculty? College Teaching 57 (1), 23-26.

Levett-Jones, T., Lathlean, J., Higgins, I., McMillan, M., 2009. Staff student relationships and their impact on nursing students' belongingness and learning. Journal of Advanced Nursing 65 (2), 316-324.

McMillan, J., 2005. Course Change and Attrition in Higher Education. Australian Council for Educational Research. Camberwell, Victoria.

Mulholland, J., Anionwu, E., Atkins, R., Tappern, M., Franks, P., 2008. Diversity, attrition and transition into nursing. Journal of Advanced Nursing 64 (1), 49-59.

National Agency for the Evaluation of Universities and Research Institutes, 2012. Autovalutazione, valutazione e accreditamento del sistema universitario Italiano. Available: http://www.anvur.org/?q=it/content/autovalutazione-valutazione-periodicae-accreditamento-pubblicazione-documento.

Orland-Barack, L., Wilhelem, D., 2005. Novices in clinical practice settings: student nurse stories of learning the practice of nursing. Nurse Education Today 25 (6), 455-464.

Pearcey, P.A., Elliott, B.E., 2004. Student impressions of clinical nursing. Nurse Education Today 24 (5), 382-387.

Pellatt, G.C., 2006. The role of mentors in supporting pre-registration nursing students. British Journal of Nursing 15 (6), 336-340.

Percy, A., Scoufis, M., Parry, S., Goody, A., Hicks, M., Macdonald, I., Martinez, K., Szorenyi-Reischl, N., Ryan, Y., Wills, S., Sheridan, L., 2008. The RED Resource, Recognition-Enhancement-Development: The Contribution of Sessional Teachers to Higher Education. Australian Learning and Teaching Council, Sydney.

Pryjmachuk, S., Easton, K., Littlewood, A., 2009. Nurse education: factors associated with attrition. Journal of Advanced Nursing 65 (1), 149-160.

Roberts, P., 1998. The service quality approach to developing user satisfaction tools Nurse Researcher 5 (3), 43-50.

Rovai, R., 2002. Development of an instrument to measure classroom community. The Internet and Higher Education 5, 197-211.

Rudel, R., 2006. Nontraditional nursing students: the social influences on retention. Teaching and Learning in Nursing 1, 47-54.

Saarikoski, M., Leino-Kilpi, H., Warne, T., 2002. Clinical learning environment and supervision: testing a research instrument in an international comparative study. Nurse Education Today 22 (4), 340-349.

Sadler, J., 2003. Effectiveness of student admission essays in identifying attrition. Nurse Education Today 23 (8), 620-627.

Salamonson, Y., Halcomb, E.J., Andrew, S., Peters, K., Jackson, D., 2010. A comparative study of assessment grading and nursing students' perceptions of quality in sessional and tenured teachers. Journal of Nursing Scholarship 42 (4), 423-429.

Scalorbi, S., Burrai, F., 2008. Clinical practice quality in BNC (Bachelor of Nursing Course). Evaluation of students' satisfaction in the Italian Red Cross School of Nursing, University of Bologna. Professioni Infermieristiche 61 (2), 67-73.

Schoech, D., Helton, D., 2003. Qualitative and quantitative analysis of a course taught via classroom and internet chatroom. Qualitative Social Work 1, 111-124.

Senge, P., 2006. The Fifth Discipline. The Art and Practice of the Learning Organisation. Doubleday/Currency, New York.

Shipman, D., Roa, M., Hooten, J., Wang, Z.J., 2012. Using the analytic rubric as an evaluation tool in nursing education: the positive and the negative. Nurse Education Today 32 (3), 246-249.

Stevens, D., Levi, A., 2005. Introduction to Rubrics: An Assessment Tool to Save Grading Time, Convey Effective Feedback and Promote Student Learning. Stylus Publishing, Sterling, VA. 
Sutherland, J.A., Hamilton, M.J., Goodman, N., 2007. Affirming at Risk Minorities for Success (ARMS): retention, graduation and success on the NCLEX-RN. Journal of Nursing Education 46 (8), 347-353.

Thedwall, K., 2008. Nontenure-track faculty: rising numbers, lost opportunities. New Directions for Higher Education 143, 11-19.

Vellone, E., Bellini, G., Fabriani, L., Fellone, C., Passeretti, F., 2007. Development of an instrument to measure quality of the Bachelor Degree in Nursing. Assistenza Infermieristica e Ricerca 26 (1), 14-23.

Vellone, E., Riegel, B., Cocchieri, A., Barbaranelli, C., D'Agostino, F., Glaser, D., Rocco, G., Alvaro, R., 2013. Validity and reliability of the caregiver contribution to self-care of heart failure index. Journal of Cardiovascular Nursing 28, 245-255.
Webb, C., Shakespeare, P., 2008. Judgements about mentoring relationships in nurse education. Nurse Education Today 28 (5), 563-571.

Wells, M.I., Dellinger, A.B., 2011. The effect of type of learning environment on perceived learning among graduate nursing students. Nursing Education Perspectives 32 (6), 406-410.

Wilkes, Z., 2006. The student-mentor relationship: a review of the literature. Nursing Standard 20 (37), 42-47. 